\title{
The Potential Impact of Community-Based Distribution Programmes on Contraceptive Uptake in Resource-poor Settings: Evidence from Ethiopia
}

Yenehun Tanye, ${ }^{1}$ Fekadu Jotie 1 , Tesfaye Shigu' ${ }^{2}$ Pierre Ngom ${ }^{3}$ and Ndugga Maggwa

\begin{abstract}
Community-based reproductive health services (CBRHS) have been in implementation in Ethiopia for over a decade. This paper assesses the impact of such programmes on contraceptive use. The data were obtained from the 2000 Ethiopian Demographic and Health Survey (DHS) and the 2003 Contraceptive Prevalence Survey (CPS). While the 2000 DHS contained a nationally representative random sample of women of reproductive age, the 2003 CPS focused on areas with active CBRHS programmes. The findings indicate that expanding the current CBRHS programme has the potential of doubling the current national contraceptive prevalence rate. (AfrJ Reprod Health 2005; 9[3]:15-26)
\end{abstract}

\section{RÉSUMÉ}

Impact potential des programmes de la distribution à base communautaire sur l'intérêt suscité par le contraceptifs dans les milieux qui manquent des ressources: Evidence venant de 1'Ethiopie. Les services de santé de la reproduction à base communautaire (SSRBC) s'engagent à la mise en oeuvre en Ethiopie depuis plus d'une décennie. Cet article fait une évaluation de l'impact de tels programmes sur l'utilisation des contraceptifs. Les données ont été recueillies à partir de l'Enquête Ethiopienne sur la Démographie et la Santé (EDS) de 2000 et de l'Enquête sur la Fréquence Contraceptive (EFC) de l'an 2003. Alors que l'EDS de 2000 comprenait un échantillon au hasard à caractère national des femmes encore en âge d'avoir des enfants, l'EFC de 2003 était concentrée sur les régions ayant des programmes actifs de SSRBC. Les résultats montrent que si le programme actuel de SSRBC est élargi, il aura le potentiel de doubler le taux de fréquence du contraceptif national actuel. (Rev Afr Santé Reprod 2005; $9[3]: 15-26)$

KEY WORDS: Community-based distribution, Ethiopia, vnmet need, contraceptive prevalence rates

Correspondence: Pierre Ngom, PhD, Senior Research Advisor, Family Health International, P. O. Box 38835, Nairobi, Kenya. Tel: +254-20-2713 913; Fax: +254-20-2726 130; E-mail:pngom@ffii.or.ke 
16 African Journal of Reproductive Health

\section{Introduction}

Community-based distribution (CBD) of contraceptives was initiated in the 1960s in Asia and Latin America. The CBD concept was then, and is still, based on the simple premise that door-todoor delivery of services can create and satisfy demand in areas with poor access to fixed family planning outlets and where such demand would have been latent and unmet otherwise. Between 1975 and 2000, the number of CBD programmes in sub-Saharan African countries increased from five to twenty. ${ }^{1-2}$ The focus of such programmes has been the delivery of short-term and barrier methods, (pills, foaming tablets, condoms) and the counselling of clients on how to use these methods, including related side effects. Because they usually operate in disease-endemic and poverty-stricken areas, CBD programmes generally incorporate basic primary health-care activities. In addition, the recent growth of the HIV/AIDS scourge and the Cairo International Conference on Population and Development (ICPD), which brought to fore the currently acclaimed global reproductive health agenda, created some shifts in the traditional components of CBD programmes in developing countries. Most community-based distribution programmes now address reproductive and general health needs in addition to the traditional family planning services they provide.

Studies aimed at assessing the impact of $\mathrm{CBD}$ on contraceptive use have been fraught with methodological flaws, debatable findings and exaggerated programme impact. Quasiexperimental studies have shown that CBD programmes have a significant positive impact on contraceptive prevalence rates, ${ }^{3-4}$ while others, using the same study design have arrived at inconclusive findings. ${ }^{5-6}$ Moreover, lessons from countries with large national CBD programmes confuse the matter further. For instance, in Kenya the plateauing of the national contraceptive prevalence rate over the past ten years ${ }^{7}$ has been blamed on the curtailment of the country's CBD programme due to funding constraints. ${ }^{8}$ In contrast, contraceptive use continues to rise in $\mathrm{Zim}$ babwe, despite the fact that the CBD's contribution to the national contraceptive prevalence rate has fallen from its previous $25 \%$ to a low of $6 \%$ in 1999. ${ }^{9-10}$

Unlike in Kenya and Zimbabwe, transition to low rates of fertility and high contraceptive uptake is still decades ahead in Ethiopia. With the second largest population size in sub-Saharan Africa, the country's total fertility rate (5.9 children per woman of reproductive age) is high, and contraceptive prevalence rate $(8.1 \%)$ is low, despite the fact that about one third of married women of reproductive age have an unmet need for family planning. Rates of infant deaths are currently at an unacceptable level -97 per $1000 .{ }^{11}$ Changes in health indicators have been slow because half of the Ethiopian population does not have access to modern health-care services. ${ }^{12}$ With respect to family planning uptake, access factors, combined with poor women's ability to travel outside the home because of low socioeconomic status, explains the record low national contraceptive prevalence rate. ${ }^{13}$ One of the national responses to these unfavourable indicators has been government's support of the implementation of community-based reproductive health services (CBRHS) programmes. Given that the bulk of the Ethiopian population live in remote rural areas with low health-care coverage, expanding and strengthening CBRHS programmes can bring services closer to underserved communities. This paper examines the potential contribution of such a strategy towards increasing family planning use in Ethiopia.

\section{The Ethiopian CBRHS Programme}

The development of community-based reproductive health services in Ethiopia is so closely linked to the history of the Family Planning Guidance Association of Ethiopia (FGAE) that it has been argued that, nationwide, nothing was known about family planning before the creation

African Journal of Reproductive Health Vol. 9 No.3 December 2005 
of FGAE. ${ }^{14}$ At the time it was founded in 1966, FGAE's only family planning services were provided from a single-room clinic run by one nurse, at the former St. Paul Hospital in Addis Ababa. ${ }^{15}$ The target population then was mainly a few clients referred to the clinic through the health-care and social welfare system. FGAE became an affiliate of IPPF in 1970 and was registered with the Ministry of Interior in 1975. It has since then expanded its services to all regions of Ethiopia. However, FGAE was only officially authorised in 1982 to carry out family planning activities as part of the national maternal and child-health programme. Since then, FGAE has taken on several additional activities, including the promotion of adolescent reproductive health programmes, family planning training for government health workers and the provision of contraceptives to health outlets countrywide.

Up till the promulgation of the 1993 National Population Policy, family planning services delivery in Ethiopia lacked strong political backing. Until the early 1990s, FGAE's work was carried out amidst unfavourable legal environment and pro-natalist views in government spheres. However, in addition to stating explicitly the goals of reducing fertility (from 7.7 in 1993 to 4.0 by 2015) and increasing contraceptive prevalence rate (from $4.0 \%$ in 1993 to $44.0 \%$ by 2015), the 1993 National Population Policy of Ethiopia also stressed the need to expand the provision of contraceptives and other reproductive health services through community-based systems. ${ }^{16}$ This constituted the main factor explaining the blossoming of community-based reproductive health programmes in Ethiopia, which culminated in the creation of the Consortium of the Family Planning (COFAP) NGOs in Ethiopia in 1995.

A national assessment of the communitybased reproductive health programme commissioned by the Ethiopian Ministry of Health in September 2002 revealed that there were thirty CBRH NGOs as at the time of that study. These
NGOs employed 12,840 community-based agents and covered 252 wards in seven regions. ${ }^{17}$ Using Phillips, et. al.'s classification of CBD models ${ }^{18}$ this assessment found that most CBRH programmes in Ethiopia followed a Type II model, i.e., doorstep household service provision by volunteers or paid CBD agents. All CBRH NGOs provided family planning services, over $90 \%$ were active in the area of STI/HIV/AIDS control, half of them provided immunization services, while only $25 \%$ carried out malaria control activities.

Although the 2002 assessment found that most clients were satisfied with the services they received, the same study also revealed that only half of the observed client/provider interactions was the information given to clients on contraceptives and HIV/AIDS of acceptable quality. Another set of key findings relate to factors explaining the performance of the $\mathrm{CBRH}$ agents. Using multivariate analysis techniques, the $\mathrm{MOH}$ led assessment team showed that there were no gender differentials in the performance of $\mathrm{CBRH}$ agents. However, high levels of education, frequent attendance at refresher training, being under close supervision, and receiving incentives were strongly associated with the agents' technical competence, the quality of services, clients' satisfaction and the number of household visits per year.

The 2002 assessment has greatly elucidated the complex nature of the structures and operations of the CBRH programme in Ethiopia. However, it did not provide any evidence that such a programme was contributing towards the goals set forth by the national population policy and by international donors. Furthermore, the low national contraceptive prevalence rates of $4 \%$ in $1990^{19}$ and $8 \%$ in $2000^{20}$ pointed to the potential weak impact on family planning uptake in Ethiopia. On one hand, the Ministry of Health held the strong view that community-based approaches to family planning service delivery was the only viable option for bringing such 
18 African Journal of Reproductive Health

services closer to the majority of Ethiopians. On the other hand, most donor agencies put the blame on inadequate data, arguing that available indicators from national sample surveys cannot be used to assess the CBRH programme they are supporting because of the small size they cover in their catchment areas.

This paper focuses on the CBRH services areas presented in Table 1. About 90\% of Ethiopia's population lives in the five national regional states (NRS) where these CBRHS programmes are located. The population covered by the CBRHS programmes in these five regions was over 10 million, that is, one out of every six Ethiopians.

\section{Methods}

Data for this paper were obtained from the 2000 Ethiopian Demographic and Health Survey (EDHS) and the 2003 Contraceptive Prevalence Survey (CPS). The 2000 EDHS covered a nationally representative random sample of 15,367 women aged 15-49 years. ${ }^{21}$ The 2003 CPS consisted of a population-based survey covering a representative random sample of 4,242 women aged 15-49 years within the CBRHS areas shown in Table 1. The CPS and DHS sampling methodologies were similar; in addition, the CPS questionnaires were adapted from those used during the 2000 EDHS. ${ }^{22}$

We compared data for married women from the 2003 CPS with the 2000 EDHS and hypothesized that any significant differences in family planning behaviour between the women canvassed by these two surveys reflect the potential impact of the community-based reproductive health programme. Aggregate levels of contraceptive prevalence rates between CBRH areas and the regions where these are located cannot lead to firm conclusions on whether the observed differences are an indication of some programme impact on women's contraceptive behaviour. To assess such impact, the odds ratio for the association between the use of modern contraception and residency in a CBRHS area was estimated and an assessment was made as to whether there was a statistically significant difference, while controlling for women's background characteristics. To carry out such test, the CPS and EDHS data were pooled together after retaining selected women's background characteristics and creating an identifier of whether or not a woman lived in a CBRHS area. Odds ratio estimates were obtained from survey logistic regressions of a woman's current use of modern contraception on whether or not the woman lived in CBRHS area, controlling for selected women's background characteristics. Unlike simple logistic procedures, survey logistic regressions take into account the effect of the survey design variables (sample weights, sampling strata and primary sampling units) on the estimates of the odds ratios' confidence intervals.

\section{Results \\ Demand for Contraception}

By making contraceptive methods and related information accessible to individuals and couples, it has been argued that community-based distribution programmes may increase overall demand for family planning. ${ }^{23}$ In Addis Ababa, Amhara and Oromiya (Table 2), the CBRHS programme had not had an effect on total demand of family planning. This is the result of a negative impact on unmet need that is compensated by an equally important positive effect on met need for family planning. For the same reasons, the effects of the CBRHS programme on total demand for limiting and spacing were also generally minimal in Addis Ababa, Amhara and Oromiya. In SNNP and Tigray regions, the CBRH programme had a positive effect on total demand for family planning, through different mechanisms. While in SNNP the effect on total demand was a result of a steep increase in met need, it was rather an increase in unmet need that explains the rise in 
The Potential Impact of Community-Based Distribution Programmes on Contraceptive Uptake in Resource-poor Settings. .

\section{Table 1 CBRHS Areas Covered by the 2003 CPS}

\begin{tabular}{|c|c|c|c|c|c|}
\hline \multirow{3}{*}{ Region } & \multirow{3}{*}{ Organisation } & \multicolumn{3}{|c|}{ Area covered by June } & \multirow{3}{*}{ Main services provided } \\
\hline & & \multirow{2}{*}{$\begin{array}{l}\text { Project } \\
\text { Started }\end{array}$} & \multicolumn{2}{|c|}{2003} & \\
\hline & & & Woreda & PA/Kebele & \\
\hline $\begin{array}{l}\text { Addis } \\
\text { Ababa }\end{array}$ & ISAPSO & 1999 & 2 & 8 & $\begin{array}{l}\text { Health education; FP; support to } \\
\text { AIDS orphans }\end{array}$ \\
\hline \multirow[t]{2}{*}{ Amhara } & $\begin{array}{l}\text { Plan } \\
\text { International }\end{array}$ & 1998 & 1 & 25 & $\begin{array}{l}\text { Health education; FP; } \\
\text { immunization, provision of food } \\
\text { supplements; construction of health } \\
\text { posts and schools; support to small } \\
\text { scale irrigation; credit services to } \\
\text { farmers }\end{array}$ \\
\hline & Eth-Aid & 1992 & 17 & 382 & $\begin{array}{l}\text { Health education; FP; provision of } \\
\text { food supplements; VCT; home- } \\
\text { based care for PLHA }\end{array}$ \\
\hline \multirow[t]{4}{*}{ Oromiya } & ADRA & 2001 & 2 & 15 & $\begin{array}{l}\text { Health education; FP; provision of } \\
\text { food supplements }\end{array}$ \\
\hline & EECMY-CS & 1999 & 14 & 325 & $\begin{array}{l}\text { Health education; FP; support } \\
\text { to AIDS orphans }\end{array}$ \\
\hline & BICDO & 2003 & 1 & 36 & $\begin{array}{l}\text { Health education; FP; support to } \\
\text { PLHA and HIV orphans }\end{array}$ \\
\hline & $\begin{array}{l}\text { CARE- } \\
\text { Ethiopia }\end{array}$ & 1996 & 9 & 38 & $\begin{array}{l}\text { Health education; FP; basic } \\
\text { renovation of and equipment for } \\
\text { clinics; training for the } \mathrm{MOH} \text { and } \\
\text { clinical staff }\end{array}$ \\
\hline \multirow[t]{3}{*}{ SNNPR } & $\begin{array}{l}\text { Eth-Kalehiwot } \\
\text { Church }\end{array}$ & 2001 & 2 & 13 & $\begin{array}{l}\text { Health education; training for peer } \\
\text { educators; organisation of school } \\
\text { clubs; FP; VCT; care and support of } \\
\text { PLHA }\end{array}$ \\
\hline & AHA & 1999 & 12 & 369 & $\begin{array}{l}\text { Health education; FP; care and } \\
\text { support for PLHA and AIDS } \\
\text { orphans }\end{array}$ \\
\hline & EECMY-SCS & 1997 & 18 & 226 & $\begin{array}{l}\text { Health education; FP; support to } \\
\text { AIDS orphans }\end{array}$ \\
\hline Tigray & REST & 2000 & 10 & 202 & $\begin{array}{l}\text { Health education; FP; ANC and } \\
\text { delivery services; immunization; } \\
\text { growth monitoring, provision of } \\
\text { food supplements; support to anti- } \\
\text { AIDS clubs and HIV/AIDS } \\
\text { orphans }\end{array}$ \\
\hline
\end{tabular}


20 African Journal of Reproductive Health

total demand in Tigray. It is noteworthy that although the CBRHS programme has increased total demand in areas where it was active, no changes were observed on total demand for spacing, because increases in met need for spacing were offset by a negative effect on unmet need for spacing. In Tigray, however, the CBRH programme had had a minor impact on total demand for spacing simply because it did not affect much both unmet and met needs for family planning. These findings suggest strongly that total demand for family planning may not be a good indicator of CBD programme success. For instance, as demonstrated above, there may be no effect of a CBD programme on total demand if the separate impacts on unmet and met needs, though significant and in the expected directions, offset each other.

Table 2 Percentage of Currently Married Women by Family Planning Need Status, CBRH Areas and Regional Averages Compared

\begin{tabular}{|c|c|c|c|c|c|c|c|c|c|c|}
\hline \multirow{2}{*}{$\begin{array}{l}\text { Demand for } \\
\text { family } \\
\text { planning }\end{array}$} & \multicolumn{2}{|c|}{ Addis Ababa } & \multicolumn{2}{|c|}{ Amhara } & \multicolumn{2}{|c|}{ Oromiya } & \multicolumn{2}{|c|}{ SNNP } & \multicolumn{2}{|c|}{ Tigray } \\
\hline & $\begin{array}{c}\text { CBRH } \\
\text { Program } \\
\text { areas } \\
(\mathrm{CPS})\end{array}$ & $\begin{array}{c}\text { Whole } \\
\text { region } \\
\text { (DHS) }\end{array}$ & $\begin{array}{c}\text { CBRH } \\
\text { Program } \\
\text { areas } \\
(\mathrm{CPS})\end{array}$ & $\begin{array}{c}\text { Whole } \\
\text { region } \\
\text { (DHS) }\end{array}$ & $\begin{array}{c}\text { CBRH } \\
\text { program } \\
\text { areas } \\
\text { (CPS) }\end{array}$ & $\begin{array}{c}\text { whole } \\
\text { region } \\
\text { (DHS) }\end{array}$ & $\begin{array}{c}\text { CBRH } \\
\text { program } \\
\text { areas } \\
\text { (CPS) }\end{array}$ & $\begin{array}{c}\text { Whole } \\
\text { region } \\
\text { (DHS) }\end{array}$ & $\begin{array}{c}\text { CBRH } \\
\text { program } \\
\text { areas } \\
\text { (CPS) }\end{array}$ & $\begin{array}{c}\text { Whole } \\
\text { region } \\
\text { (DHS) }\end{array}$ \\
\hline \multicolumn{11}{|l|}{ Unmet need (a) } \\
\hline For spacing & 4.7 & 8.1 & 13.6 & 21.2 & 20.5 & 23.1 & 17.5 & 24.3 & 19.2 & 18.8 \\
\hline For limiting & 8.9 & 11.1 & 14.0 & 19.7 & 12.0 & 13.3 & 12.5 & 11.2 & 14.6 & 9.1 \\
\hline Total & 13.6 & 19.2 & 27.6 & 40.9 & 32.5 & 36.4 & 30.0 & 35.5 & 33.8 & 28.0 \\
\hline \multicolumn{11}{|l|}{ Met need (b) } \\
\hline For spacing & 20.2 & 21.3 & 10.2 & 3.1 & 8.4 & 3.2 & 9.6 & 2.7 & 5.8 & 6.1 \\
\hline For limiting & 29.1 & 23.0 & 10.2 & 4.4 & 6.3 & 3.4 & 11.6 & 3.7 & 7.0 & 4.1 \\
\hline Total & 49.3 & 45.2 & 20.4 & 7.5 & 14.7 & 6.6 & 21.2 & 6.4 & 12.8 & 10.2 \\
\hline \multicolumn{11}{|l|}{ Total demand (c) } \\
\hline For spacing & 24.9 & 29.4 & 23.8 & 24.3 & 28.9 & 26.3 & 27.1 & 27.0 & 25.0 & 24.9 \\
\hline For limiting & 38.0 & 34.9 & 24.2 & 24.1 & 18.3 & 16.7 & 24.1 & 14.9 & 21.6 & 13.2 \\
\hline Total & 62.9 & 64.3 & 48.0 & 48.3 & 47.2 & 43.0 & 51.2 & 41.9 & 46.6 & 38.1 \\
\hline \multicolumn{11}{|c|}{$\%$ of demand satisfied (d) } \\
\hline For spacing & 81.1 & 72.4 & 42.9 & 12.8 & 29.1 & 12.2 & 35.4 & 10.0 & 23.2 & 24.5 \\
\hline For limiting & 76.6 & 68.5 & 42.1 & 18.3 & 34.4 & 20.4 & 48.1 & 24.8 & 32.4 & 31.1 \\
\hline Total & 78.4 & 70.3 & 42.5 & 15.5 & 31.1 & 15.3 & 41.4 & 15.3 & 27.5 & 26.8 \\
\hline$\overline{\mathrm{N} \text { (unweighted) }}$ & 62 & 236 & 654 & 2,587 & 971 & 3,769 & 681 & 2,133 & 390 & 627 \\
\hline
\end{tabular}

$N B:(c)=(a)+(b)$ and $(d)=(b) /(c)$;

A woman is considered as having an unmet need for spacing if she is fecund, is neither pregnant nor amenorrboeic; is not using any family planning method and would like to wait two or more years before having ber next birth. To this group are added women who were pregnant and who said that their current pregnancy was mistimed, and those who were amenorrhoeic, whose last live birth was mistimed and who were not currently using family planning. A similar definition for unmet need for limiting is obtained by considering desire for no more cbildren for fecund women, pregnancy 'unwantedness' for pregnant women, and 'unwantedness' of the last live birth for amenorrboeic women. Unmet need for family planning is the sum of unmet needs for spacing and limiting. A woman has a met need for spacing if she is using family planning and says that she wants to have another child or is undecided whether to have another child. Women with met need for limiting are those who are currently using a family planning method and who report that they want no more children. Women with met need for family planning comprise those with met need for spacing and those with met need for limiting. Total demand for family planning is the sum of unmet and met needs for family planning. 
The Potential Impact of Community-Based Distribution Programmes on Contraceptive Uptake in Resource-poor Settings . . 2

\section{Contraceptive use}

The most significant and consistent impact of the CBRHS programme in Ethiopia is on met demand, or current use of contraception. Compared to local regional averages, current use of contraception among women living in the CBRHS programme areas was three times higher for Amhara and SNNP, and twice higher for Oromiya, than the local regional averages (Table 3). Such an effect was much lower in Addis Ababa and nil in Tigray. However, the CBRHS programme has made greater contributions towards increasing contraceptive use for spacing than for limiting (Table 2). Except in Tigray where no effect is discernable, the gradient in the level of contraceptive use between the CBRHS areas and the regions where they are located is higher for spacing than for limiting demand. These differences in contraceptive use are mimicked by the empirical variations in the percentage of satisfied demand (Table 2).

Differentials in aggregate levels of contraceptive prevalence rates do not take into account individual differences in women's background characteristics, which were highly correlated with the use of contraception. To assess the potential impact of the CBRHS programme on individual contraceptive behaviour, it is important to control for differences in background characteristics. Odds ratio estimates presented in Table 3 were obtained from survey logistic regressions of a woman's current use of modern contraception on whether or not the woman lives in a CBRHS area, controlling for selected women's background characteristics. Except in Tigray where no substantial difference was observed, living in an area covered by a CBRHS programme significantly increased a woman's likelihood of using modern contraception, even after controlling for region, place of residence, education, age, desire for additional children, and household wealth. The odds of using contraception for women living in CBRHS areas are highest in Oromiya, lowest in Addis Ababa and nil in Tigray.

Figure 1 shows the percentage of married women using contraception by method. Most women in CBRHS areas used injectables, followed by the pill. The prominence of injectables and the pill as the major components of the contraceptive method mix in the CBRHS areas is also observed at the national level. One major programme effect that emerges clearly from Figure 1 is the much higher proportions of married women turning to clinical methods, compared to the national picture as depicted by the EDHS. Although CBRHS agents provided only pill, foaming tablets and condoms, they were capable of triggering the use of other methods through proper counselling and referrals to fixed outlets where such contraceptives are available.

Table 3 Odds Ratios (OR) for the Association between Modern Contraceptive Use and Residency in a USAID-Funded Area, Married Women Only $(n=10,879)$, Pooled 2003 CPS and 2000 EDHS Data

\begin{tabular}{lcc}
\hline Region & Odds Ratios $^{*}$ & (95\% Confidence Interval) \\
\hline Addis Ababa & 2.1 & $1.1-4.0$ \\
Amhara & 3.6 & $2.3-5.7$ \\
Oromiya & 4.9 & $3.0-8.1$ \\
SNNP & 2.7 & $1.3-5.6$ \\
Tigray & 1.8 & $0.7-4.5$ \\
\hline All & 2.9 & $2.1-3.9$ \\
\hline
\end{tabular}

* Adjusted for urban/rural residence, education, age, desire for additional children, and household wealth. 


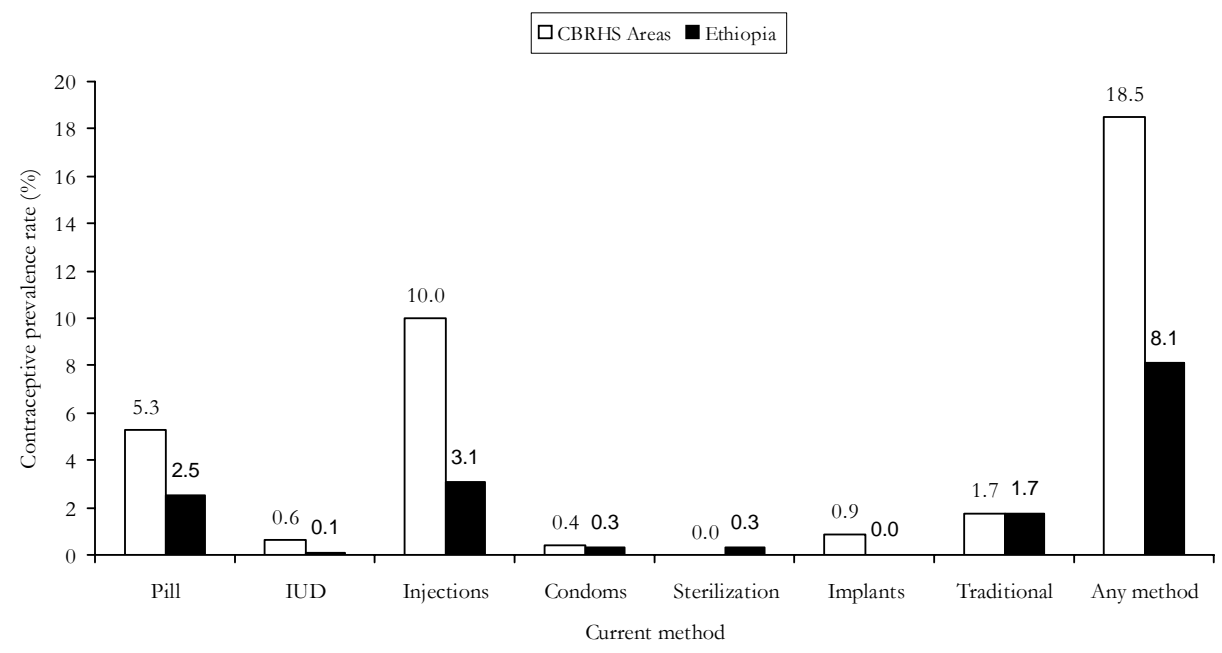

Figure 1 Method-Specific Contraceptive Prevalence Rates, CBRHS Areas (2003 CPS) and Ethiopia (2000 EDHS)

\section{Discussion and Conclusions}

The membership of the Consortium of Reproductive Health Associations in Ethiopia (CORHA), formerly the Consortium of Family Planning Associations (COFAP), has grown from seven to over sixty NGOs from 1995 to date. These NGOs differ in their service delivery approaches, the criteria they use for recruiting and training their agents, and how such agents are compensated. Although the Ethiopian Ministry of Health has developed a training curriculum for CBRHS programmes operating in the country, the content of such a document has not been imparted adequately to community-based reproductive health workers. This was reflected in the 2002-2003 national assessment, which showed that half of the CBRHS agents interviewed were not fully competent to provide pills to their clients. ${ }^{24}$ Perhaps this is only a tip of the iceberg of distrust between CBRHS NGOs and the Government of Ethiopia, which has been blamed by CORHA for smooth talks to local
NGOs while hindering their activities through heavy bureaucracy. ${ }^{25}$

Several small-scale impact evaluations, generally using a pre- and post-test design, have been carried out in Ethiopia over the past twelve years. An assessment of the first CBD project implemented in Ethiopia in 1992 in Jimma zone (Oromiya Region) concluded that it raised contraceptive prevalence from $1 \%$ to $15 \%$ in five years. ${ }^{26}$ Other studies have also shown that $\mathrm{CBRH}$ programmes increase contraceptive use, often with an impact probably exaggerated, if not excessively too large to be sustainable. FGAE's CBD programme in Eastern Shoa (Oromiya State) was shown as having increased contraceptive prevalence from $5 \%$ to $44 \%$ in just three years. ${ }^{27}$ In the SNNP areas where the EECMY-SCS' CBD programme was established in 1997, it has been argued that this programme raised the contraceptive prevalence from $4 \%$ to $36 \%$ in just three years. ${ }^{28}$ Unfortunately, all these studies are localised in nature and, hence, the 
The Potential Impact of Community-Based Distribution Programmes on Contraceptive Uptake in Resource-poor Settings . . .

replicability and sustainability of the programmes being evaluated are questionable.

The empirical evidence presented in this paper shows that the CBD activities increased demand for family planning in only one out of the five regions covered by such a programme. In this region (Tigray), the CBRHS programme was in an earlier phase compared to those in the other four regions. Consequently, programme effects in Tigray resulted mainly in an increase in unmet need and a modest rise in met need, thus leading to an overall increase in total demand for family planning. In other regions where the CBD services were provided for a longer duration, however, total demand was not affected because the programme's negative impact on unmet need was offset by significant positive effects on contraceptive use. Although intuitively correct, the common view that community-based distribution creates demand for family planning must be nuanced by the fact that such a relationship depends strongly on the maturity of the CBD programme.

Taking into account women's socioeconomic characteristics is important when assessing CBD impact on individual contraceptive behaviour, because community-based distribution programmes typically serve rural populations that are poorer and less educated than national averages. In turn, wealth, education, and place of residence are strong determinants of contraceptive use. Even after controlling for their background characteristics, women living in areas covered by the CBRHS programme were three times more likely to use contraception than the average Ethiopian woman. Clearly, CBRHS services in Ethiopia have the potential of significantly increasing contraceptive prevalence at the national level. Alas, sustainability is the major standing hurdle in expanding the coverage of such programmes. Almost all NGOs delivering CBRH services rely heavily on external funding, and no mechanisms are in place to respond to donor's fatigue; which is a major weakness. For instance, when in 2004 GTZ withdrew its support to the Ethiopian community-based distribution programme, half of the CBRHS areas in the country were suddenly left without CBD services. ${ }^{29}$ The challenge in Ethiopia (and elsewhere in subSaharan Africa) is that seemingly sustainable solutions such as the use of volunteers as CBD agents, cost-sharing, or community financing, either are not often feasible or are not simply the best approaches and may even lead to programme failure.

Because contraceptives may introduce social discord, leading at times to intimate partners' violence amongst African couples, women of low bargaining powers often resort to family planning methods that are suitable to covert use..$^{30-31}$ Women can take injections of depo-provera while visiting a health facility and remain protected against unwanted pregnancies for three months. This may be done without their husband's knowledge and without the bother of having to remember to take the pill or to undergo clinical procedures that are involved when opting for implants or intrauterine devices. Consequently, a general pattern that has been observed in the contraceptive method mix in sub-Saharan Africa and elsewhere in the developing world is the predominance of injectables. ${ }^{32-34}$ The Ethiopian DHS data analysed here indicate clearly that the ratio of pill users to injectable users is 1:1.2 nationally, while the corresponding ratio is $1: 2$ for CBRHS areas, according to the CPS results (Figure 1).

Obviously, the CBRHS agents play a catalytic role in local demand for injectables by referring a large number of their clients to the fixed health facility where these contraceptives are available. Through their household visits, CBRHS agents are able to create and/or strengthen informed choice about injectables beyond what it would have been without the CBD programme. It is likely that meeting the growing need for injectables will require the national CBRH programme to be more innovative in increasing access to this method. There is no evidence, however, that 
24 African Journal of Reproductive Health

training CBD workers to administer injectables will lead to higher uptake of this method at aggregate level, compared to the alternative strategy of strengthening the CBD referral system so that clients who need injectables are directed to fixed health outlets where qualified medical staff can attend to their needs.

Currently, it is estimated that more than 3 million Ethiopian women aged 15-49 years have an unmet need for family planning, and such an unmet demand is likely not to be met without the expansion and strengthening of the community-based distribution of family planning methods nationwide. ${ }^{35}$ Millions of families would have been reached with contraceptive services if the current CBRHS services were expanded nationally. It is reasonable to assert that as a result the national contraceptive prevalence rate of $8 \%$ would have at least doubled, if it were likely for such indicator to have increased to a level similar to that observed in the CBRHS areas.

\section{Acknowledgements}

This publication was made possible through support provided by the Office of Population and Reproductive Health Bureau for Global Health, US Agency for International Development, under the terms of Cooperative Agreement No. GPO-A00-05-00022-00. The opinions expressed herein are those of the authors and do not necessarily reflect the views of the US Agency for International Development.

\section{REFERENCES}

1. Kols AJ and MJ Wawer. Community-based health and family planning. Population Reports Series 1982; L: 3.

2. Phillips JF, WL Greene and Elizabeth Jackson. Lessons from community-based distribution of family planning in Africa.
Policy Research Division Working Paper, Population Council, New York, 1999; 121.

3. Katz K, CG West, F Doumbia and F Kane. Increasing access to family planning services in rural Mali through community-based distribution. Inter Fam Plann Persp 1998; 24(3): 104-110.

4. Debpuur C, JF Phillips, EF Jackson, A Nazzar, P Ngom and FN Binka. The impact of the Navrongo project on contraceptive knowledge and use, reproductive preferences and fertility. Stud Fam Plann 2002; 33(2): 141164.

5. Ampofo DA, DD Nichols, S Ofusu-Amah, $S$ Blumenfeld and AK Neumann. The Danfa family planning program in rural Ghana. Stud Fam Plann 1976; 7(10): 266-274.

6. Bertrand JT, N Mangani and M Mansilu. The acceptability of household distribution of contraceptives in Zaire. Inter Fam Plann Persp 1984; 10(1): 21-26.

7. Central Bureau of Statistics (CBS) (Ministry of Planning and National Development), Ministry of Health $(\mathrm{MOH})$, Kenya Medical Research Institute (KEMRI), Centers for Disease Control and Prevention (CDC), [Kenya] and Measure DHS + [ORC MACRO]. Kenya Demographic and Health Survey 2003: Preliminary Report. Calverton, Maryland: CBS, MOH, KEMRI, CDC and ORC MACRO, 2003.

8. Mati JK. Family Planning Needs in the Context of the HIV / AIDS Epidemic: Kenya Preliminary Report. Nairobi: Family Health International, 2004.

9. Wazara MC. Initial Assessment of the Expanded CBD Program, Harare, Zimbabwe. National Family Planning Council, 2002.

10. Moyo I. Family Planning Needs in the Context of the HIV/AIDS Epidemic: Zimbabwe, Preliminary Report. Harare: Family Health International, 2004.

11. Central Statistical Authority (CSA) [Ethiopia] and ORC Macro. Ethiopia

African Journal of Reproductive Health Vol. 9 No.3 December 2005 
The Potential Impact of Community-Based Distribution Programmes on Contraceptive Uptake in Resource-poor Settings . . ${ }_{25}$

Demographic and Health Survey 2000. Calverton: CSA and ORC Macro, 2001.

12. Ministry of Health $(\mathrm{MOH})$ [Ethiopia]. Health and Health Related Indicators. Addis Ababa: Planning and Programming Department, $\mathrm{MOH}, 2001$.

13. Ahmed J and G Mengistu. Evaluation of Program Options to Meet Unmet Need for Family Planning in Ethiopia. Calverton: ORC Macro, 2002.

14. Hailemariam A. Family planning services in Ethiopia: problems and prospects. Paper presented at a Workshop on Establishment of a Mechanism for Promotion of Family Planning Services, Consortium of Family Planning Associations of Addis Ababa, Ethiopia, 16 June 1995, 17-33.

15. Tesfaye A. Twenty five years of Family Guidance Association services: its achievements, drawback and future prospects. In: Family Guidance Association of Ethiopia: Twenty Five Years of Family Planning Services: 19661991. Addis Ababa: Family Guidance Association of Ethiopia, 1991; 3-33.

16. The Transitional Government of Ethiopia (TGE). National Population Policy of Ethiopia. Addis Ababa: Office of the Prime Minister, TGE, 1993.

17. Ministry of Health (MOH) [Ethiopia]. Assessment of Community Based Reproductive Health Services in Ethiopia, 2002-2003. Addis Ababa: Family Health Department, $\mathrm{MOH}$, 2004.

18. Op. cit., see No. 2.

19. Central Statistical Authority (CSA) [Ethiopia]. The 1990 Family and Fertility Survey: Preliminary Report. Addis Ababa: CSA, 1991.

20. Op. cit., see No. 11.

21. Op. cit., see No. 11.

22. Tawye Y, F Jotie and P Ngom. Contraceptive Prevalence Survey of USAID funded Areas of Ethiopia, 2003. Addis Ababa: Family Health International, 2004.
23. Simmons R, L Baqee, MA Koenig and JF Phillips. Beyond supply: the importance of female family planning workers in rural Bangladesh. Stud Fam Plann 1988; 19(1): 29_ 38.

24. Op. cit., see No. 17.

25. Alemu WT. Role of NGOs in implementing the National Population Policy - prospects and challenges. In: Proceedings of the National Workshop on Population and Development in Ethiopia: A Decade's Overview, June 17, 2003, Addis Ababa, 2004; 43-44.

26. Gobena D. Final Project Evaluation of the Jimma Family Planning Community Based Distribution Project. Addis Ababa: Family Guidance Association of Ethiopia, 1998.

27. Sisay W. Evaluation Report of Involving Rural Women's Development Agents in Community Based Contraceptive Distribution. Addis Ababa: Family Guidance Association of Ethiopia, 1998.

28. Mengistu A, T Melesse, B Bibiso and T Bedada. Follow-up Evaluation of the Effect of the EECMY Community Based Reproductive Health (CBRH) Project in Hadiya and KAT Zones of SNNP Region, Ethiopia. Addis Ababa: Pathfinder International, 1999.

29. Op. cit., see No. 17.

30. Biddlecom AE and B Fapohunda. Covert contraceptive use: prevalence, motivations and consequences. Stud Fam Plann 1998; 29(4): 360-372.

31. Bawah Ayaga Agula, Patricia Akweongo, Ruth Simmons and James Phillips. Women's fears and men's anxieties: the impact of family planning on gender relations in northern Ghana. Stud Fam Plann 1999; 30(1): 54-66.

32. Shah I. Comparative analysis of contraceptive method choice. In: Proceeding of the Demographic and Health Surveys World Conference, 5-7 August 1991, Washington DC, 617-625. 
26 African Journal of Reproductive Health

33. Ross J, K Hardee, E Mumford and S Eid. Contraceptive method choice in developing countries. Inter Fam Plann Persp 2002; 28(1): 32-40.
34. Magadi M and S Curtis. Trends and determinants of contraceptive method choice in Kenya. Stud Fam Plann 2003; 34(3): 149_ 159.

35. Op. cit., see No. 13. 